\title{
Experience of nurses in the process of donation of organs and tissues for transplant ${ }^{1}$
}

\author{
Edvaldo Leal de Moraes ${ }^{2}$ \\ Marcelo José dos Santos ${ }^{3}$ \\ Miriam Aparecida Barbosa Merighi ${ }^{4}$ \\ Maria Cristina Komatsu Braga Massarollo ${ }^{5}$
}

\begin{abstract}
Objective: to investigate the meaning of the action of nurses in the donation process to maintain the viability of organs and tissues for transplantation. Method: this qualitative study with a social phenomenological approach was conducted through individual interviews with ten nurses of three Organ and Tissue Procurement Services of the city of São Paulo. Results: the experience of the nurses in the donation process was represented by the categories: obstacles experienced in the donation process, and interventions performed. The meaning of the action to maintain the viability of organs and tissues for transplantation was described by the categories: to change paradigms, to humanize the donation process, to expand the donation, and to save lives. Final considerations: knowledge of the experience of the nurses in this process is important for healthcare professionals who work in different realities, indicating strategies to optimize the procurement of organs and tissues for transplantation.

Descriptors: Nursing; Tissue and Organ Procurement; Organ Transplantation; Tissue Transplantation; Brain Death; Qualitative Research.
\end{abstract}

\footnotetext{
${ }^{1}$ Paper extracted from doctoral dissertation "Experience of nurses in the donation process of organs and tissues for transplantation" presented to Escola de Enfermagem, Universidade de São Paulo, São Paulo, SP, Brazil.

2 PhD, RN, Hospital das Clínicas, Faculdade de Medicina, Universidade de São Paulo, São Paulo, SP, Brazil.

${ }^{3} \mathrm{PhD}$, Professor, Escola de Enfermagem, Universidade de São Paulo, São Paulo, SP, Brazil.

${ }^{4}$ PhD, Full Professor, Escola de Enfermagem, Universidade de São Paulo, São Paulo, SP, Brazil.

${ }^{5}$ PhD, Associate Professor, Escola de Enfermagem, Universidade de São Paulo, São Paulo, SP, Brazil.
}

Corresponding Author:

Edvaldo Leal de Moraes

Universidade de São Paulo. Faculdade de Medicina

Hospital das Clínicas. Serviço de Procura de Órgãos e Tecidos

Av. Dr. Enéas de Carvalho Aguiar, 255, sala 5017-A

Bairro: Cerqueira César

CEP: 05403-000, São Paulo, SP, Brasil

E-mail: edvaldoleal@uol.com.br
Copyright ( 2014 Revista Latino-Americana de Enfermagem This is an Open Access article distributed under the terms of the Creative Commons Attribution Non-Commercial License (CC BY-NC).

This license lets others distribute, remix, tweak, and build upon your work non-commercially, and although their new works must also acknowledge you and be non-commercial, they don't have to license their derivative works on the same terms. 


\section{Introduction}

The process of donating organs and tissue for transplantation is complex, and the participation of nurses is essential for the provision of organs and tissues to society, which will benefit from this therapy. Thus, one of the daily activities of this professional is to identify patients with suspected brain death (BD), through an active search in Intensive Care (ICU), postanesthesia and emergency units ${ }^{(1)}$.

After identifying the potential donor, with clinical signs of brain death (irreversible coma, unresponsive and unperceptive), the nurse initiates the technical procedures and protocols that confirm the condition of the individual as a potential donor(1). Faced with this situation, when starting the procedures for the confirmation of brain death, the nurse guides the healthcare team regarding the need to inform the potential donor's family and clarifies any doubts they may have. This care is of paramount importance because often donor families only have contact with the diagnosis of $\mathrm{BD}$, after its conclusion, making it difficult to accept this condition(2).

In this situation, it is essential that the family understand this concept and accept that the person has died. Thus, the skill of the healthcare team in communication is critical to ensure the clarity and objectivity of the information conveyed to these families. The professionals who work with critically ill patients should receive specific training in communication, as this is a basic tool for the performance of their daily activities. This aspect is very important when communicating brain death to the family of the donor and aims to prepare them, so that the nurse can perform the family interview to request the donation of organs and tissues for transplantation(3).

Another moment of extreme relevance in the donation process refers to the maintenance of the brain dead potential donor, with this care aiming to maintain the viability of the organs for transplantation. This care intends to save the lives or improve the quality of life of those in need of organs and tissues. Thus, the donor is the means to a determined end. This perspective probably motivates the action of the nurses in the donation process, giving meaning and importance to their work ${ }^{(4)}$.

Given this scenario, the nurse can be considered a key element in obtaining of organs and tissues for transplantation and maintaining their viability, possibly because the aim of their actions is to optimize the quality of the offered organs, to provide transparency for the donation process, and to ensure the greatest possible number of donors, consequently contributing to the success of organ transplant and tissue implant programs. However, there are few studies that have explored the experience of this social group.

A bibliographical study on the scientific production of Brazilian nurses related to organ donation and transplantation showed that the majority of Nursing publications concentrated mainly on the transplant theme, especially with regards to kidney and liver ${ }^{(5)}$. The study showed that there is a knowledge gap in relation to approaching the experience of nurses in the donation process and the significance of the actions of these professionals in maintaining the viability of organs and tissues for transplantation. Thus, some concerns emerged: how do the nurses experience the donation of organs and tissues for transplant process? How do they perceive the participation of the multidisciplinary team in this process? What do they expect with their actions in this scenario? What elements enable or hinder this process?

This study aimed to investigate the meaning of the actions of nurses in the process of donation of organs and tissues for transplantation. Comprehending the reality experienced by the agents involved in this phenomenon is essential in order to capture its essence.

The world of life is the scenario of social actions, being understood as a natural world that imposes limits on the attitudes of individuals, where people act and operate as actors in a reality that is modified by their actions and that, conversely, transforms their actions $^{(6)}$

The action is the human behavior projected by the actor in a self-conscious way. People act in terms of motivations directed toward objectives that highlight the future, these are called "in-order-to-motives". Conversely, people have reasons for their actions and worry about them. These reasons, rooted in past experiences and in the personality that individuals developed throughout their lives, are called "becausemotives"(7).

Motive can be understood as "a state of things, the objective to be achieved with the action". Thus, "inorder-to-motives" are the guidelines for future action and "because-motives" are related to past experiences. The comprehension of the other necessarily passes through the knowledge of the motives that influence the realization of their actions ${ }^{(7)}$. The nurses of the Organ and Tissue Procurement Services constitute a social 
group with projects and motives to act in the process of donation of organs and tissues for transplantation that need to be comprehended.

Therefore, this study could provide healthcare professionals who work directly or indirectly with donation and transplantation with factors that may delimit the care practices in this field of health, provide insights to guide the teaching and care practices in this specialty, foster the implementation of public policies, as well as highlight the need for the application of investment in ongoing training of these professionals.

\section{Method}

In this study, a qualitative approach was used, with the framework of Social Phenomenology of Alfred Schutz. This theoretical and methodological framework allows human phenomena guided by a daily concrete experience to be comprehend, thus allowing the investigation of the group of nurses who work with the donation process to obtain and maintain the viability of organs and tissues for transplantation.

The study was conducted with ten nurses of three Organ and Tissue Procurement Services of the city of São Paulo. Each service had 11 nurses that worked exclusively with the process of organ and tissue donation for transplantation.

The researcher made personal contact with the coordinators of these services and, at that time, presented the aims of the project and clarified the doubts relevant to the study. A list of the names of the nurses who worked in the sector was also requested. After this phase, telephone contact was made with each nurse, in order to explore their interest in participating in the study and, when they expressed a desire to participate, the meeting was scheduled, according to their availability in relation to the day, time and place that the interview could take place.

The data collection was carried out through individual face to face interviews, with an average duration of 2 hours each. These were performed within the services, the study scenarios, between September 2011 and June 2012, directed by the following guiding questions: could you tell me your experience in the process of donation of organs and tissues for transplant? What do you expect with your practice in this process?

The number of subjects was established during the course of the interviews rather than in advance, from the content of their statements, and the interview phase was terminated when it was realized that the discourses were being repeated, i.e., the motives that drove the actions of nurses working in the process of donation and maintaining the viability of organs and tissues for transplantation.

The analysis of the results was conducted according to the steps proposed by Social Phenomenology researchers ${ }^{(8)}$, which consisted of a systematic procedure for analyzing the interviews, through careful reading and rereading, always seeking to understand in all of them the essence of the experience of the nurses in the donation process of organs and tissues for transplantation; grouping of the significant aspects extracted from the discourses of the subjects through thematic convergences, which were grouped in order to grasp the subjective meaning that the nurses assigned to their own actions; analysis of these categories seeking to comprehend the "in-order-to-motives", and the "because-motives" of the nurses' action of maintaining the viability of organs and tissues for transplantation; and the discussion of the results in light of the Social Phenomenology of Alfred Schutz and other references related to the theme.

To identify the various interviews, the designations E1, E2...E10 were used in order to preserve the anonymity of the nurses. The study met the international ethical standards for research involving humans, with approval by the Research Ethics Committee, under No. 0998/09.

\section{Results}

The experience of the nurses in the process of donation of organs and tissues for transplantation (because-motives) was represented by the categories: obstacles experienced in the donation process, and interventions performed.

\section{Obstacles experienced in the donation process}

Through excerpts of the statements drawn from the interviews, it is possible to observe that the quotidian of the nurses in the process of donation of organs and tissues for transplantation is marked by obstacles, represented by the shortage of human and material resources and also by the lack of healthcare professionals in relation to this process. This directly interferes in the identification of the potential donor, in performing the diagnosis of brain death and in the communication with the family members, in maintaining 
the viability of the organs for transplantation, in the family interview, and in the release the donor's body for burial. The participants of this study reported that the difficulties begin with identifying the potential donor and, at that time, there is difficulty to start the BD diagnosis: [...] when you make an active search and when you identify a patient with a Glasgow score of three and ask the physician to start the brain death protocol, at that moment we already encounter the first difficulty. Many physicians resist starting this protocol (E2).

Once the potential donor has been identified, the physician should the carry out the examinations for brain death diagnosis. There are physicians who do not know how to perform this diagnosis due to lack of training, experience and contact with this situation in the academic and professional life: [...] there are many physicians who have difficulty in performing the examination for the diagnosis of brain death, I presume this is due to lack of experience and training (E1). [...] We're faced with professionals who can not make this diagnosis [...] who did not have training in the academic area (E4).

The nurses emphasized that the excess of work of the healthcare team and the shortage of human and material resources interfere in the performance of the brain death diagnosis and the potential donor ends up staying in the background: [...] in some hospitals with few human resources, with less material resources, there is difficulty in obtaining the brain death diagnosis. [...] you're at the mercy of a system that has a significant shortage of physicians (E9).

Furthermore, the maintenance of the donors is flawed, because they remain in the background in the care: $[\ldots]$ maintaining the donor is still not well resolved, $[\ldots]$ people do not understand that the donor requires the same care as an intensive care patient. [...] if the donor needs to be transferred to the intensive care unit, this will not happen. [...] The donor remains in the background (E6).

The nurses also perceived that the maintenance of the donor is impaired due to the overload of work and inadequate physical and human resources in the health system: [...] there are hospital where the emergency room is full, the ICU is full, very serious patients, work overload for the nursing and medical staff, and the maintenance of the potential donor is impaired (E1).

In the family interview, the nurses considered the inadequate care provided to the family of the donor as a complicating factor: [...] when we go to talk with the family, it is the moment they will express outrage at the care they received. [...] this impedes the performance of the family interview (E10).
Another aspect that interferes in the family interview is the inadequacy in the physical structure of the hospitals, which contributes to the lack of privacy and humanization in this step of the donation process: [...] we should have an adequate space to interview the family, because it is terrible interviewing a family in a place where all the time people enter and keep interrupting us (E7).

The nurses cited difficulties in cases of violent death, due to the delay in releasing the deceased's body from the Medical Legal Institute (MLI): [...] there is still a very long delay at the Medical Legal Institute to release the body of the donor. [...] the family has to keep waiting, waiting, waiting for the release of the body of their loved one, I think it borders on disrespect (E5).

In cases of natural death (stroke, brain tumor etc.), in some hospitals there is no staff to prepare the deceased's body, leaving this responsibility to the family: [...] some hospitals, for example, do not dress the body of the donor and decide that this is a function of the family, and this really shocks the family of the donor (E10).

The account of the barriers experienced by the nurses of the Organ and Tissue Procurement Services in the donation process was unanimous regarding these difficulties, with these professionals performing interventions aimed at overcoming the obstacles.

\section{Interventions performed}

Regarding the identification of the possible donor, an appropriate intervention at this stage of the donation and transplantation process is the education of professionals about the importance of this speciality for the healthcare system: [...] to show people the importance of identifying the potential donor, to talk with the physician and with the multidisciplinary team and to answer questions, teach and educate, these are very important interventions that I carry out in my day to day of work (E3).

Another important intervention is to clarify the doubts of the family members of the potential donor related to the initiation of the brain death examinations, as this provides greater transparency in the donation process: [...] My concern, at the opening of the protocol, is that the family is informed, so they can feel secure. Therefore, I insist that the physician tells the family about what will be done, as this provides greater transparency to the donation and transplantation process (E2).

The nurses consider that clarity in the communication of the brain death diagnosis to the donor's family provides them with the possibility to autonomously decide about the donation of the organs 
and tissues: [...] we end up explaining to the family the reason why their relative is brain dead. [...] it is often through us that the family understands the concept of brain death, and this enables the family members to autonomously decide about the donation (E6).

Proper maintenance of the eligible donor is an essential step to ensure the viability of the organs for transplantation, and the participation of nurses is essential to detect disturbances and request the appropriate interventions from the physician: [...] I do not leave the side of the donor until he arrives at the operating room. I have to carry out intensive care to ensure the quality of donated organs (E3).

The family interview is the stage in which the nurses can help the family of the donor, providing clarification and support in the decision making: [...] during the interview, you inform the family that there is the possibility of donation. [...] to support the family and offer assistance in this difficult time is very important. I always offer support independent of the family's decision (E4).

One nurse emphasized that the care offered to the family members of the eligible donor, after the explantation of the organs and tissues, improves the relationship with them: [...] it is the nurse who releases the donor's family, and I think we accompany the family until the MLI, until the funeral, I believe this improves the relationship with the donor's family and humanizes the donation process (E8).

The meaning of the action of the nurses in maintaining the viability of the organs and tissues for transplantation was described by the following categories: changing paradigms, humanizing the donation process, increasing donations and saving lives.

\section{Changing paradigms}

When planning the action, the nurses considered the education of healthcare professionals and of the general public a valuable tool for promoting a change in paradigms. [...] Our role in the donation process, is not only to provide organs [...] it is also to educate, to teach, it is to make the population less ignorant about donation. [...] to pass on knowledge, teach and promote a change of attitude (E9).

\section{Humanizing the donation process}

The nurses believed that, to humanize the donation process, it is important to establish a relationship of help with the families of potential donors, as they considered that this action facilitates the interaction with them, aiming to reduce the grief of the family and provide resources, so that they may face the loss of their relative. [...] we have to offer help and support to the family. [...] to create a support network for this family is very important. [...] from the physician, nurse, psychologist, social worker, this network of support makes the difference in the end (E1).

Humanizing the donation process is a need present in nursing practice, and the ability to actively listen is essential in this process. [...] you are trying to alleviate a little of the pain that this family is feeling. Sometimes the family just wants to talk and you need to know how to listen [...] this is fundamental (E7).

\section{Increasing donations}

As the changes are happening, the nurses design actions, aiming to increase donations and, consequently, transplants: [...] I hope that, with my work, I am contributing to the increase, more and more, in the number of organ donors, because we know that many patients are on the waiting lists (E5).

\section{Saving Lives}

The actions of the nurses are also designed in order to save lives. To obtain and maintain the viability of organs for recipients that, for these professionals, have no name or face, motivates and gives meaning to the work. [...] to help save lives or improve the quality of life for those who need an organ to continue to live, people you will ever meet and that, in some way, will benefit (E9).

\section{Discussion}

In Brazil, the system is only officially notified of one out of every eight potential donors. The main obstacles in obtaining organs for transplantation consists of failure to identify, notify and confirm this situation, due to ignorance, disinterest and overload of work of the healthcare professionals. The delay or failure at this point results in inappropriate costs, prolonged occupation of ICU beds, an increase in family suffering, and the loss of organs and tissues for transplantation. Therefore, the availability of trained personnel in hospitals is important to improve the notification of potential donors ${ }^{(9)}$. These data confirm the findings of the present study, when the nurses reported that the difficulties experienced in the donation process begin with the identification of the potential donor, standing out as a complicating element that causes delays in the performance of the procedures for confirmation of the brain death diagnosis. 
At present, the scientific, technological and organizational advances that aim to increase the number of transplants of organs and tissues cannot be disregarded, as they allow many people to benefit from this form of treatment. However, the shortage of donors to meet the growing demand of patients on the waiting list is possibly the greatest obstacle in the performance of transplantation procedures(10-11).

Even though the criteria for brain death are well defined, there are still physicians who consider this situation different from death ${ }^{(12)}$. This perception is shared by the participants of this study, when they affirmed that the difficulties in this step of the donation process are compounded by ignorance, inexperience and resistance from some physicians in relation to accepting the diagnosis of brain death as the death of the person. In this sense, it is necessary to invest in education aimed at healthcare professionals and to deconstruct the uncertainties of physicians regarding the diagnosis of brain death.

Furthermore, due to the lack of human resources the potential donor is the patient that receives less care in the Intensive Care Unit, with the attention of the healthcare team targeted towards potentially recoverable patients with a prognosis of life ${ }^{(13-15)}$. This finding is similar to the present study, when the nurses pointed out the complicating aspect of the shortage of human and material resources that contribute to the donor not being a priority in the health context, being relegated to the background in the care.

The healthcare services present the professionals with many ethical problems, often due to the scarcity of resources according to the needs of the users. Choosing which patient will benefit more in the situation of an insufficient number of Intensive Care beds is a difficult and even undesirable task ${ }^{(16)}$.

All potential donors should be cared for in the ICU for better monitoring of the clinical complications resulting from brain death. The unavailability of this resource interferes with the quality of the care provided to the potential donor ${ }^{(9)}$. This reality is also perceived by the nurses working in the process of donation of organs and tissues for transplantation.

For a person to comprehend the acts of another, they need to first know the "in-order-to-motives" and the "because-motives" of these acts. It is only possible to comprehend these acts if the person is in the same situation and guided by the same motives as the other ${ }^{(6-7)}$. Therefore, to include healthcare professionals in the donation scenario, possibly facilitates the understanding of the motives that lead organ harvesting nurses to consider the participation of all important to overcome the difficulties.

The nurses play a key role in maintaining the potential donor, because of their close proximity to these individuals and the ability to recognize the physiological changes resulting from brain death, so that the medical team can establish the most appropriate management for the situation. Therefore, the nursing care is important to ensure good quality organs for the transplant recipients ${ }^{(17)}$. The participants of this study stated that the presence of the physician and nurses is essential in the management of the hemodynamic changes of the donor and represents the intervention, which in fact makes the provision of good quality organs for transplantation possible.

When the nurse experiences the world of the quotidian life of donation and identifies the obstacles, these are safe guides to interpret the social reality, with the importance that is attributed to these difficulties being a determinant in the design of actions that allow the change in the paradigms of the healthcare professional, humanization of the care to the family members of the deceased donor, and, consequently, an increase in the donation of organs and lives saved. Therefore, the social relationships between nurses and other healthcare professionals present this intersubjectivity, and interpersonal communication becomes crucial in this context, since these individuals establish complementary interactions, mutually influencing their actions ${ }^{(6)}$.

Effective communication plays an important role in the donation process as it provides the necessary clarification for the family related to making decision about the donation of organs and tissues for transplantation ${ }^{(18)}$. This data confirms the findings of the present study, when the nurses reported that objectivity, clarity and simplicity in the transmitted information help the family members of eligible donors to make decisions autonomously.

In this sense, education of the multidisciplinary healthcare team and of the general public is essential to strengthen the participation of all in the process of donation of organs and tissues for transplantation, being one of the determining factors for the success of the transplants programs ${ }^{(10,19)}$. This statement corroborates the findings of the present study, as the nurses said that to change the paradigms, it is important to intensify the education of the healthcare team and the general public. 
For these articulators of the donation, humanizing means offering help to the family members of the deceased donor, so that they can mobilize coping mechanisms faced with the situation of brain death, empathy being a resource used by these subjects, allowing them to speak with these family members adequately, comprehending the situation, their feelings, behaviors and suffering ${ }^{(1,10)}$.

For the healthcare professionals and the general public, the great motivation to donate organs and tissues for transplantation is the benefit received by many people. One potential donor in good condition can provide benefit, through the transplants of their various organs and tissues, to more than ten patients ${ }^{(19-20)}$. This perspective motivates the actions of nurses who work with the process of donation of organs and tissues for transplantation.

\section{Final considerations}

When reflecting on their experiences in the process of donation of organs and tissues for transplantation, the nurses realized that the obstacles presented by the shortage of human and material resources, as well as the ignorance of the multidisciplinary team regarding this healthcare specialty, interfere with the identification of the potential donor, with the diagnosis of brain death, with communicating this condition to the family members, with maintaining the viability of organs for transplantation, with the family interview, and with the release of the donor's body for burial.

Given this scenario, this social actor performs interventions aimed at overcoming the obstacles and reveals future projects and expectations that aim to change the paradigms of the healthcare professionals in relation to the donation of organs and tissues, so that these individuals can humanize the process, providing dignified care to the family members of the potential donors. With these actions, the nurse intends to increase donation and save lives.

Considering the reality presented by the participants of this study, the need to change this scenario is evident, with education having been identified as undoubtedly the most appropriate way to conquer these challenges, to implement strategies to overcome these obstacles, and to optimize the viability of organs and tissues for the performance of transplantations.

The fact that this study only involved one social context should be considered a limiting factor, which does not allow the results to be generalized. However, its importance is anchored in the experience of the nurses, which makes it possible to comprehend the meaning of the action that these professionals experience in their quotidian of work in the process of organ and tissue donation and transplantation.

\section{References}

1. Moraes EL, Massarollo MCKB. Family refusal to donate organs and tissue for transplantation. Rev. Latino-Am. Enfermagem. 2008;16(3):458-64.

2. Bousso RS. The family decision-making process concerning consent for donating their child's organs: a substantive theory. Texto Contexto Enferm. 2008;17(1):45-54.

3. Santos MJ, Moraes EL, Massarollo MCKB. Communicating bad news: ethical dilemmas before situations of encephalic death. O Mundo da Saúde. 2012;36(1):34-40.

4. Lima AAF, Silva MJP, Pereira LL. Sufrimiento $y$ cotradicción: el significado de la muerte y Del morir para los enfermeros que trabajan en el proceso de donación para trasplante. Enferm Global. 2009;15:1-17.

5. Cicolo EA, Roza BA, Schirmer J. Organ donation and transplantation: brasilian nursing publications. Rev Bras Enferm. 2010;63(2):274-8.

6. Schutz A. El problema de la realidad social: escritos I. $2^{a}$ ed. Buenos Aires: Amorrortu; 2008.

7. Wagner HR. Sobre fenomenologia e relações sociais. Rio de Janeiro: Vozes; 2012.

8. Merighi MAB, Oliveira DM, Jesus MCP, Hoga LAK, Pedroso AGO. Experiences and expectations of women submitted to hysterectomy. Texto Contexto Enferm. 2012;21(3):608-15.

9. Dell Agnolo CM, Freitas RA, Toffolo VJO, Oliveira MLF, Almeida DF, Carvalho MDB. Causes of organ donation failure in Brazil. Transpl Proc. 2012;44:2280-2.

10. Flodén A, Foreberg A. A phenomenographic study of ICU-nurses' perceptions of and attitudes to organ donation and care of potential donors. Intensive Crit Care Nurs. 2009;25(6):306-13.

11. Paez G, Valero $R$, Manyalich $M$. Training of health care students and professionals: a pivotal element in the process of organ donation awareness and professionalization. Transpl Proc. 2009;41:2025-9.

12. Bitencourt AGV, Neves FBCS, Durães $L$, Nascimento DT, Neves NMBC, Torreão LA, et al. Evaluation of medical students knowledge on brain death. Rev Bras Ter Intensiva. 2007;19(2):144-50. 
13. Souza SS, Borenstein MS, Silva DMGV, Souza SS, Carvalho JB. Nursing strategies for coping with the care of a potential organ donor. Rev Rene. 2013;14(1):92-100.

14. Sanner MA, Nydahl A, Desatnik P, Rizell M. Obstacles to organ donation in Swedish intensive care units. Intensive Care Med. 2006;32(5):700-7.

15. Pestana $A L$, Erdmann AL, Sousa FGM. Emerging the complexity of nursing care facing a brain death. Esc Anna Nery. 2012;16(4):734-40.

16. Fortes PAC, Pereira PCA. Patient priorization in medical emergencies: an ethical analysis. Rev Assoc Med Bras. 2012;58(3):335-40.

17. Peiffer KM. Brain death and organ procurement. Am J Nurs. 2007;107(3):58-67.

18. Siminoff LA, Marshall HM, Dumenci L, Bowen G, Swaminathan A, Gordon N. Communicating effectively about donation an educational intervention to increase consent to donation. Prog Transplant. 2009; 19(1):35-43.

19. Ríos A, Ramírez P, Rodríguez MM, Martínez-Alarcón L, Lucas D, Alcaraz J, et al. Benefit of a hospital about organ donation and transplantation: an evaluation by spanish hospital transplant personnel. Transpl Proc. 2007;39(5):1310-3.

20. Guetti NR, Marques IR. Nursing assistance to the potential organ donor with brain death. Rev Bras Enferm. 2008;61(1):91-7. 